
\title{
MORPHOLOGICAL ANALYSIS OF IONOMERS
}

\author{
January 1, 1993- December 31, 1993
}

\section{Extended X-ray Absorption Fine Structure Studies of Ionomers}

Two systems have been studied in detail, lightly sultonated polystyrenes and polyurethane cationomers. In the first material, the nickel, zinc and cadmium-neutralized ionomers were investigated and the details of the cation local environment was elucidated through the use of the simulation package FEFF5 ${ }^{\otimes}$. The cationomer was a polyurethane with a poly(tetramethylene oxide) soft segment and a 4,4'diphenylmethane diisocyanate hard segment chain extended with a quaternized diol. EXAFS was used to determine the change in the local environment of the neutralizing anion bromine as the temperature was raised.

For the lightly sulfonated polystyrenes, the availability of a detailed $a b$ initio simulation package, FEFF5 ${ }^{\circledR}$ from the University of Washington, allowed the determination of the local structure at a level of detail not previously possible. A system of equations was written using EXAFS generated bond distances and local geometric constraints which allowed for the development of atomic coordinates. These coordinates were then input into FEFF5 and the simulated EXAFS spectra was compared with the experimental spectra. This procedure was used to determine which atomic arrangement provided the best fit to the actual spectra as well as values for the Debye-Waller factor, which is a measure of aggregate disorder.

The local environment around the nickel and zinc-neutralized materials was very similar, even though nickel is octahedrally coordinated to oxygen and zinc is tetrahedrally coordinated to oxygen. In both cases, the cation was coordinated to oxygen from sulfonate groups, while the second shell consisted of sulfur. In both cases, the Metal-Oxygen-Sulfur angle was between 135-140 ${ }^{\circ}$. The small size of the 
aggregates $(\sim 1-2 \mathrm{~nm})$ requires that these well-ordered structures terminate in some manner, and it was hypothesized that water provided the oxygen necessary to fill the cation coordination environment near the aggregate boundaries: Simulations indicated that the cadmium-neutralized material was also octahedrally coordinated to oxygen, but two of the oxygen atoms were from water and only four were from sulfonate groups.

The structure of the bromine-neutralized cationomer is still unresolved. Structures generated from the EXAFS spectra of the small molecule compound tetramethyl ammonium bromide, which should have a very similar local bromine structure to the cationomer, did not agree with the published crystal structure. However, the purpose of this study was to differentiate between two possible causes for an endothermic peak found in differential scanning calorimetry (DSC) experiments. A similar peak is also found in ethylene-methacrylic acid (E-MAA) ionomers and has been attributed to the loss of order within the aggregates, i.e. ionic crystallite melting. Other studies on this same polymer have shown that EMAA will absorb water even when stored under nominally anhydrous conditions. EXAFS studies on this bromine-neutralized cationomer indicate that this endothermic peak is the result of water absorption by the polymer. This water absorption occurred even though the polymer was stored over anhydrous $\mathrm{CaSO}_{4}$. This study highlighted the extreme sensitivity of ionomers to water and also suggests that the endothermic peak in E-MAA ionomers may also be the result of water absorption.

\section{Nuclear Magnetic Resonance of Lightly Sulfonated Polystyrenes}

Solid-state ${ }^{23} \mathrm{Na}$ NMR is being used to study the local environment of the cation in sodiumneutralized lightly sulfonated polystyrene. The purpose of these experiments is to identify sodium atoms by their immediate surroundings. These experiments have led to differentiation between nuclei that exist

in aggregates and nuclei that are isolated in the polymer matrix. Sodium ions dispersed throughout the polymer matrix do not contribute to the aggregate physical crosslinks that result in the improved physical 
properties of these ionic materials as compared to the unmodified polymers. Therefore, isolated ions are less desirable.

Peaks at three different chemical shifts have been observed, indicating that the sodium atoms exist in at least three different local environments. One of these is a broad peak, centered around $-12 \mathrm{ppm}$ assigned to sodium ions that are in restricted environments, such as those held in aggregates. The wide distribution of sites present in the aggregates leads to a large distribution of chemical shift values and broadens the ${ }^{23} \mathrm{Na}$ NMR peak. A narrow peak at a higher chemical shift value ( $7 \mathrm{ppm}$ ) has been assigned to isolated sodium ions. The fraction of these isolated ions decreases with increasing ionization level. Finally, a third peak at $0 \mathrm{ppm}$ is sometimes present. Through humidification experiments, this peak has been assigned to hydrated sodium ions. Relaxation studies and reference spectra have been used to help in identification of these species.

Studies on the effects of thermal treatment on the distribution of ions in these materials show an increase in the fraction of isolated ions with heat treatment. In contrast, the general charasteristics of the aggregate peak are relatively unaffected by thermal treatment. The fraction of isolated ions is a function of the treatment time and presence of trace water in the aggregates. The ap')earance of isolated ions with heating is most likely due to water transport from the aggregates at these elevated temperatures. As the water molecules are forced out of the aggregate, they drag weakly theld ionic groups into the polymer matrix. Humidification experiments have also been conduct \& to seternire the effect of added water on the ions. Following exposure to excessive humidity dium are in a hydrated environment; the ${ }^{23} \mathrm{Na}$ NMR spectrum shows only a single peak at $1 \rho p r i$ Sishsequent cirying resuits in a redistribution of the sodium ions, with a higher fraction hid in agrests than existed prior to

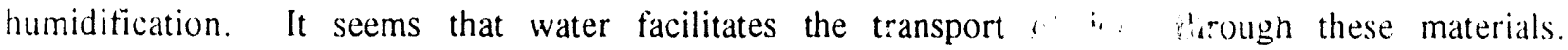
Humidification experiments are being continued to determine the suative accessibility of each environment to water. 
In order to determine the effect of polydispersity on the ion distribution, experiments have been initiated on monodisperse sulfonated polystyrene. During these experiments, the effect of both ionic content and polymer molecular weight will be studied. Preliminary results on these materials have shown that distinct differences exist in the ${ }^{23} \mathrm{Na}$ NMR spectra of the monodisperse and polydisperse ionomers when compared at the same molecular weight and ion content. At the present time, no conclusions have been drawn as to the nature of these differences.

\section{Solution Studies of Carboxy-Telechelic Polystyrene Ionomers}

Small-angle neutron scattering (SANS) experiments have been performed to explore the role of temperature in solutions of sodium-neutralized carboxy-telechelic polystyrene ionomers in toluene using the same labelling techniques previously used in SANS studies of the same systems at constant temperature $\left(25^{\circ} \mathrm{C}\right)$. By adjusting the labelling levels and the angular range, SANS experiments probe either the aggregate structure or the single chain structure. The aggregate studies were conducted on two ionomers with ionic levels of 1.1 and 3.7 mole\% in the temperature regime from $25^{\circ} \mathrm{C}$ to $80^{\circ} \mathrm{C}$ at the same concentration where the viscosity upturn was observed at $25^{\circ} \mathrm{C}(1.5 \mathrm{~g} / \mathrm{dl}$ and $2.4 \mathrm{~g} / \mathrm{dl}$ for the 1.1 and 3.7 mole\% ionomers respectively). The 3.7 mole\% ionomer was also tested at a higher concentration of $7.5 \mathrm{~g} / \mathrm{dl}$ where the effect of temperature was expected to be stronger. The upturn in the scattering patterns that is characteristic of association in these solutions was found to decrease with increasing temperature which indicates that the extent of association decreases with temperature in agreement with viscometric measurements. The effect of temperature on single chain dimensions was tested at 1.5 and $7.5 \mathrm{~g} / \mathrm{dl}$ for the 1.1 mole\% ionomer and at $7.5 \mathrm{~g} / \mathrm{dl}$ for a 2.6 mole\% ionomer.

Data analysis was completed for both the SANS experiments that were performed at $25^{\circ} \mathrm{C}$ and at elevated temperatures. The aggregate scattering data were fitted to the deGennes model over the entire q-regime studied. The statistical segment length of the polymer chain shows a slight but definite increase as concentration increases, approaching a plateau at the highest concentration studied, $7.5 \mathrm{~g} / \mathrm{dl}$. The 
plateau value for the 3.7 mole\% ionomer agrees within experimental error with the value measured for this same ionomer in the solid state. However, the single chain dimensions were smaller than the unionized ester under the same conditions. The $\chi$ interaction parameter increased substantially with decreasing concentration, which was quite unexpected. An increase in $\chi$ indicates worsening solvent quality, which would be expected to be occur as the extent of association increases. As expected, $\chi$ was smaller for the ester than the ionomer. The Debye model, modified to take into account the fact that toluene is a good solvent for the polystyrene backbone, fit the single chain data very well at all polymer concentrations and temperatures studied except at the highest concentration for the 2.6 mole\% ionomer.

The fitting of these data with a wormlike chain model, which accounts for the short chains of the ionomer, is also planned. Both the concentration and temperature dependence of the statistical segment length that is directly obtained from the single chain data analysis is successfully predicted by the deGennes model, which is an indication that the model is appropriate for describing the multimer scattering data. Extension of the deGennes model to account for specific ionic interactions is continuing.

Temperature had a negligible effect on the statistical segment length at all concentiations and ionic levels studied. The $\chi$ parameter decreased slightly with temperature consistent with nonionic polymer solutions. Scattering data obtained at the lowest q-regime was described well by the Zimm equation. From the Zimm analysis it was shown that the extent of both the aggregation and the aggregate dimensions are unaffected by the ionic content in the concentration regime studied; a quite surprising result since ionic level is expected to have a major role in the mechanism of association in ionomer solutions. SANS experiments have been scheduled to investigate if this behavior is valid over a more extended concentration regime. An increase in temperature decreased both the extent of association as well as the radius of gyration of the multimers, even at the lowest concentrations studied. These results support a model in which increasing temperature reduces the intermolecular interactions and leads to smaller size clusters consisting of a fewer number of chains. 


\section{DISCLAIMER}

This report was prepared as an account of work sponsored by an agency of the United States Government. Neither the United States Government nor any agency thereof, nor any of their employees, makes any warranty, express or implied, or assumes any legal liability or responsibility for the accuracy, completeness, or usefulness of any information, apparatus, product, or process disclosed, or represents that its use would not infringe privately owned rights. Reference herein to any specific commercial product, process, or service by trade name, trademark, manufacturer, or otherwise does not necessarily constitute or imply its endorsement, recommendation, or favoring by the United States Government or any agency thereof. The views and opinions of authors expressed herein do not necessarily state or reflect those of the United States Government or any agency thereof. 


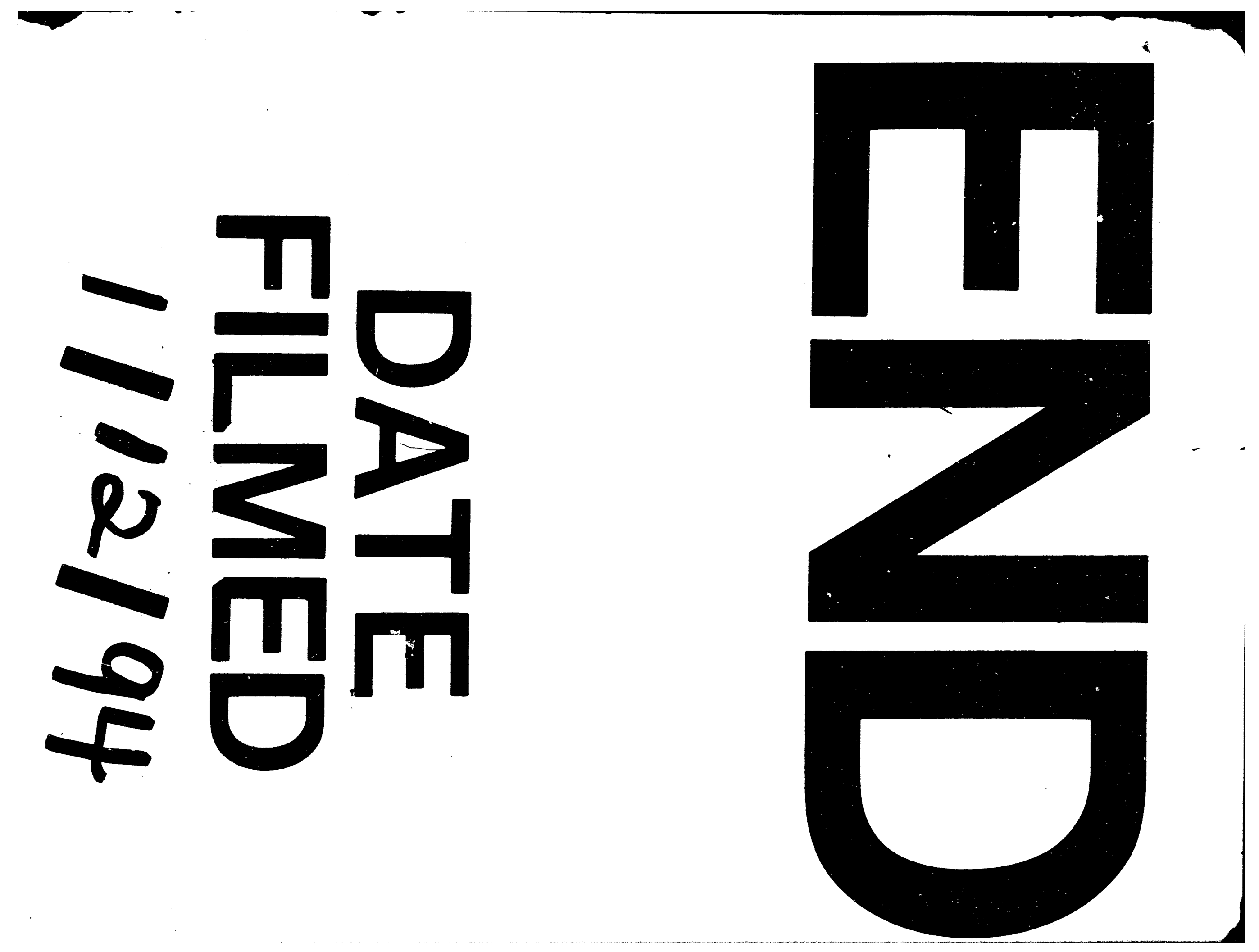




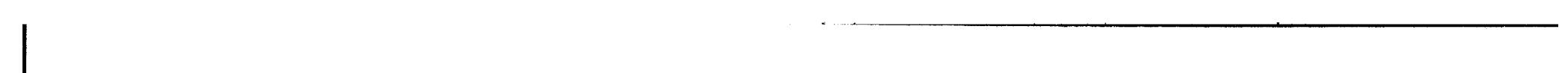

